\title{
Standardization and Metrology for Efficiency and Reliability in Microbeam Analysis - No pain, no gain
}

\author{
Vasile-Dan Hodoroaba ${ }^{1}$, Ryna B. Marinenko, ${ }^{2}$ Mike Matthews ${ }^{3}$ and Jiang Zhao ${ }^{4}$ \\ 1. BAM Federal Institute for Materials Research and Testing, Division 6.8 Surface Analysis and \\ Interfacial Chemistry, 12200 Berlin, Germany. \\ 2. National Institute of Standards and Technology (NIST), Materials Measurement Science Division, \\ Microanalysis Research Group, Gaithersburg, MD 20899, USA. \\ 3. 17 Circuit Lane, RG30 3HB Reading, Great Britain. \\ 4. Institute of Chemistry, SAC, \#2 Zhong Guan Cun Bei Yi Jie Beijing, 100190, China.
}

Standardization and metrology are two terms which are used rather rarely at major conferences as well as in scientific publications in the field of microbeam analysis. For laboratories operating under an accreditation scheme the operator of the microscope/microprobe must have available internal, national or international written standards which should be applicable to any quantitative analysis. Hence, requirements, specifications, guidelines or characteristics of methods, instruments or samples are provided with the final goal that these can be used consistently. In this way it is ensured that microbeam analyses results are reliable and meet quality-management requirements [1].

Standardization organizations operating at national level such as ANSI (USA), BSI (GB), DIN (Germany), SAC (China) or JISC (Japan) synchronize their activities to the international organization for standardization, ISO. In the field of microbeam analysis the ISO technical committee TC 202 is in charge with the harmonization of technical specifications of products and services making industry more efficient and breaking down barriers to international trade. Since the TC 202 establishment in 1991 eighteen ISO standards including updates have been published. The current list and the projects in development is updated on the ISO webpage [2], see Fig. 1. A main and continuous task of TC 202 and its subcommittees is to identify and evaluate feasible projects/proposals needed to be developed into new international standards. A short overview of the ongoing projects will be given.

As regards the metrological aspects, The International Bureau of Weights and Measures (BIPM) through the Consultative Committee for the Amount of Substance (CCQM) is concerned with the metrological aspect in Chemistry and Biology. The development of the technical and organizational infrastructure of the International System of Units (SI) as the basis for the world-wide traceability of measurement results occurred here [3]. In particular, the Surface Analysis Working Group (SAWG) assists in identifying and establishing inter-laboratory work to test the consistency as well as to improve the traceability of spatially resolved chemical surface analysis at the micro and nanoscale. Examples of recent and ongoing projects related to microbeam analysis will be presented. The relevance of the evaluation of the complete chain of measurement uncertainties towards ensuring the traceability and comparability of the results will be emphasized through examples [4]. Thereby the compliance of the results of the microbeam analysis with the ISO document "Guide to the expression of uncertainty in measurement (GUM)" [5] will be explained.

Another international platform in the frame of which pre-standardization work can be organized is VAMAS (Versailles Project on Advanced Materials and Standards) [6]. International collaborative projects involving mainly national metrological institutes aim at providing the technical basis for 
harmonized measurements, testing, specifications, and standards. One key point of VAMAS activities is constituted by inter-laboratory comparisons. In the field of microbeam analysis the technical working area (TWA) 37 Quantitative Microstructural Analysis as well as TWA 34 Nanoparticle Populations deal with corresponding projects.

The contribution is meant not only to give a short overview of the existing standardisation and metrology activities in the field of microbeam analysis, but to bring possibilities and needs closer to the users. Especially younger personnel should be aware of these rather disliked parts of the microbeam analysis. At the same time motivation of conference participants to generate potential new projects is a hidden scope of the present contribution.

\section{References:}

[1] ISO/IEC 17025 (2005) General requirements for the competence of testing and calibration laboratories. ISO, Geneve.

[2] http://www.iso.org (Standard developments / Technical Committees / ISO/TC 202 Microbeam analysis).

[3] http://www.bipm.org/en/committees/cc/ccqm/

[4] V-D Hodoroaba et al., Microsc. Microanal. 20 (Suppl 3), 2014, p. 730.

[5] ISO/IEC Guide 98-3:2008 Uncertainty of measurement Part 3: Guide to the expression of uncertainty in measurement (GUM:1995), Geneva: Internat. Org. Stds, 101 pp.

[6] http://www.vamas.org/

ISO/TC 202 - Microbeam analysis

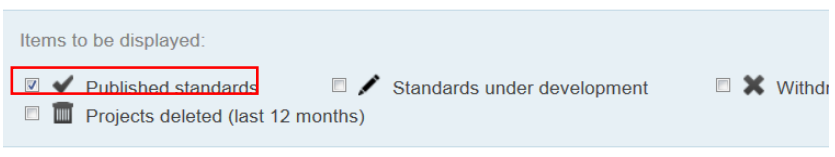

Standards and projects under the direct responsibility of ISO/TC 202 Se

- Standard and/or project

$\checkmark$ ISO $15632: 2012$

Microbeam analysis -- Selected instrumental performance parameters for the specification and

checking of energy-dispersive $\mathrm{X}$-ray spectrometers for use in electron probe microanalysis

$\checkmark$ ISO 14595:2014

Microbeam analysis -- Electron probe microanalysis -- Guidelines for the specification of

certified reference materials (CRMs)

$\checkmark$ ISO 14594:2014

Microbeam analysis -- Electron probe microanalysis -- Guidelines for the determination of

experimental parameters for wavelength dispersive spectroscopy

$\checkmark$ ISO 29301:2010

Microbeam analysis -- Analytical transmission electron microscopy -- Methods for calibrating
ISO/TC 202 - Microbeam analysis

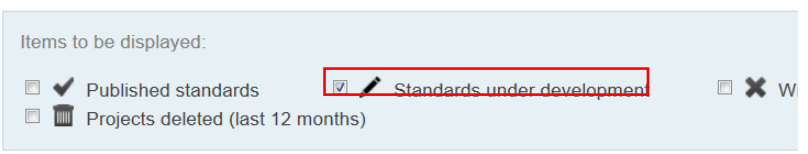

Standards and projects under the direct responsibility of ISO/TC 202

- Standard and/or project

ISO/CD 16700

Microbeam analysis -- Scanning electron microscopy -- Guidelines for calibrating image

magnification

ISO/AWI 19463

Microbeam Analysis -- Quality assurance procedures and reference materials for the

calibration and diagnostic assessment of electron probe microanalysis instruments utilizing

wavelength dispersive spectrometers

ISO/DTR 19640

Guide to practical chemical state analysis in EPMA

- ISO/AWI 20171

Tag image file format for Scanning electron microscopy(TIFF/SEM)

ISO/WD 20263

Microbeam Analysis -- Analytical transmission electron microscopy -- Methods for

Figure 1. Screenshots with standards published by ISO/TC 202 (left) and with standards under development (right) [2]. 